\title{
Infectivity of porcine circovirus type 2 DNA in semen from experimentally-infected boars
}

\author{
Darin M. Madson ${ }^{1}$, Sheela Ramamoorthy ${ }^{2}$, Chris Kuster ${ }^{3}$, Narinder PaL ${ }^{1}$, \\ Xiang-Jin MenG $^{2}$, Patrick G. Halbur ${ }^{1}$, Tanja Opriessnig ${ }^{1 *}$ \\ ${ }^{1}$ Department of Veterinary Diagnostic and Production Animal Medicine, College of Veterinary Medicine, \\ Iowa State University, Ames, Iowa, USA \\ ${ }^{2}$ Department of Biomedical Sciences and Pathobiology, Center for Molecular Medicine and Infectious Diseases, \\ College of Veterinary Medicine, Virginia Polytechnic Institute and State University, Blacksburg, Virginia, USA \\ ${ }^{3}$ Kuster Research and Consulting, 22509 East 1680th Street, Geneseo, Illinois, 61254, USA
}

(Received 16 July 2008; accepted 29 October 2008)

\begin{abstract}
Porcine circovirus type 2 (PCV2) is an economically important pathogen. It has been demonstrated that PCV2 DNA can be detected in boar semen by PCR; however, the biological relevance of this is unknown. The objectives of this study were to determine if semen positive for PCV2 DNA is infectious (1) in a swine bioassay, or (2) when used for artificial insemination. For the first objective, 4-week-old pigs were inoculated intraperitoneally with PCV2 DNA-negative (bioassay-control; $n=3$ ), PCV2a DNA-positive (bioassay-PCV2a; $n=3$ ), or PCV2b DNA-positive (bioassay-PCV2b; $n=3$ ) raw semen, or PCV2 live virus (bioassay-positive; $n=3$ ), respectively. Pigs inoculated with PCV2 DNA-positive semen and PCV2 live virus became viremic and developed anti-PCV2 antibodies indicating that the PCV2 DNA present in semen was infectious. For the second objective, three Landrace gilts were inseminated with PCV2 DNA-negative semen (gilts-controls) from experimentally-infected boars, and six gilts were artificially inseminated with semen positive for PCV2a DNA (gilts-PCV2a; $n=3$ ) or PCV2b DNA (gilts-PCV2b; $n=3$ ). Serum samples collected from the gilts in all groups remained negative for anti-PCV2 antibodies for the duration of the experiment. In addition, fetal serum samples from all 105-day-gestation fetuses were negative for anti-PCV2 antibodies or PCV2 DNA. Under the conditions of this study, PCV2 DNA-positive semen was not infectious when used to artificially inseminate gilts; however, it was demonstrated to be infectious in a swine bioassay model and therefore is a potential means of PCV2 transmission amongst swine herds.
\end{abstract}

artificial insemination / bioassay / boar / PCV2 / semen

\section{INTRODUCTION}

Porcine circovirus type 2 (PCV2) is associated with many disease entities among growing and mature swine, including reproductive failure in pregnant females [31]. In breeding herds, natural infection of pregnant animals with PCV2 has been associated with reproductive failure manifested as abortions, mummification of fetuses and stillbirths with

*Corresponding author: tanjaopr@iastate.edu identification of PCV2 antigen associated with lesions in fetal tissues [17,26,57].

Vertical transmission of PCV2 can occur due to viremia of the dam leading to transplacental infection of in utero fetuses $[17,26,34,57]$. The virus is capable of replicating in fetal tissues [13, 42, 59] and has a tropism for mitotically active cells within tissues which change depending on fetal age [43].

Currently little is known about the role of $\mathrm{PCV} 2$ in semen and the transmission of PCV2 
to dams or fetuses. Artificial insemination has become standard practice by most large production systems in North America in recent decades which followed the trend occurring in Europe [9]. In 2001, it was estimated that nearly $60 \%$ of the swine herds in North America were practicing artificial insemination [50] as compared with Europe where estimates approach $90 \%$ or greater $[9,19,21]$. The main advantage of artificial insemination is genetic improvement [37]. However, semen may be a source for virus introduction and rapid spread [11], and monitoring boar centers particularly for porcine reproductive and respiratory syndrome virus (PRRSV) is a common practice to prevent disease transmission [41]. Currently, monitoring for PCV2 is not routinely done at Veterinary Diagnostic Laboratories.

Detection of PCV2 DNA in semen has been accomplished by using nested PCR (nPCR) techniques [14, 18, 23], quantitative real-time PCR (qPCR) [33], and virus isolation [14]. PCV2 DNA was found to be shed intermittently or continuously in experimentally challenged boars $[18,20]$. The amount of PCV2 DNA in semen is generally in low quantities and serum viremia usually precedes detection in semen $[18,20]$. In addition, shedding of PCV2 DNA in semen has been reported up to 27.3 months in naturally infected boars [23]. All associated sex glands contain PCV2 DNA after infection [20] and PCV2 antigen can also be detected in interstitial macrophages and fibroblast-like cells in sex glands of affected boars [29].

To date, it is unclear whether the PCV2 present in semen is infectious and if artificial insemination with PCV2 DNA-positive semen can cause PCV2 transmission or reproductive failure. To assess the infectivity of PCV2 DNA in semen and its role in transmission of PCV2, two studies were designed: The first objective was to determine if PCV2 DNA-positive semen is infectious in a swine bioassay model. The second objective was to determine whether PCV2 DNA-positive semen used for artificial insemination is infectious to PCV2 naïve gilts, can be transmitted to offspring, or induce reproductive failure.

Page 2 of 11 (page number not for citation purpose)

\section{MATERIALS AND METHODS}

\subsection{Animals}

\subsubsection{Swine bioassay study}

Twelve four-week-old mixed breed pigs were purchased from a commercial farm negative for antibodies to PCV2, PRRSV, and swine influenza virus (SIV).

\subsubsection{Artificial insemination study}

Nine three-week-old purebred Landrace gilts were purchased from a farm negative for antibodies to PRRSV and SIV and positive for antibodies to PCV2.

\subsection{Semen}

Raw semen negative for PCV2 DNA, raw semen positive for PCV2a DNA, and raw semen positive for PCV2b DNA used in this study was collected from a PCV2 experimental trial in which boars were intranasally and intramuscularly inoculated with PCV2a and PCV2b, respectively $[20,33]$. The PCV2a isolate (ISU-40895) and the PCV2b isolate (NC-16845) were originally obtained from finishing pigs with microscopic lesions consistent with PCVAD and associated with PCV2 antigen. Both isolates have previously been shown to cause disease in experimentally-infected pigs [32]. The raw semen samples tested negative for the presence of porcine circovirus type 1 (PCV1) DNA, porcine parvovirus (PPV) DNA, or PRRSV RNA by PCR $[3,15]$. Aliquots of fresh raw semen were saved and placed into sterile $5 \mathrm{~mL}$ polystyrene round-bottom tubes $\left(\mathrm{Falcon}^{\circledR}, \mathrm{BD}\right.$ Biosciences, San Jose, CA, USA) and stored at $-80^{\circ} \mathrm{C}$. The remaining raw semen was extended at a 1:1 dilution with a commercially available semen extender (TriXcell, IMV International, Minneapolis, MN, USA), which was warmed to match semen temperature, and the extended semen was then cooled to approximately $17^{\circ} \mathrm{C}$. A portion of each semen sample was further diluted with semen extender to approximately 5 billion sperm per $80 \mathrm{~mL}$ insemination dose. The extended semen was stored at $17^{\circ} \mathrm{C}$ for up to $96 \mathrm{~h}$ and rotated twice daily.

\subsection{Animals, housing, experimental design, and inoculation}

Both experimental protocols were approved by the Iowa State University Institutional Animal Care and Use Committee. 
Table I. Swine bioassay study: Experimental design.

\begin{tabular}{lccccc}
\hline Group & $n^{\mathrm{a}}$ & Inoculum & Amount & Dose & Route \\
\hline Bioassay-control & 3 & PCV2 DNA-negative semen & $7 \mathrm{~mL}$ & - & IP* \\
Bioassay-PCV2a & 3 & PCV2a DNA-positive semen & $7 \mathrm{~mL}$ & $10^{5.6 \mathrm{~b}}$ & IP \\
Bioassay-PCV2b & 3 & PCV2b DNA-positive semen & $7 \mathrm{~mL}$ & $10^{5.8 \mathrm{~b}}$ & IP \\
Bioassay-positive & 3 & PCV2 live virus & $3 \mathrm{~mL}$ & $10^{4.5 \mathrm{c}}$ & IP \\
\hline
\end{tabular}

a Number of pigs in each group;

${ }^{\mathrm{b}} \mathrm{PCV} 2$ genomic copy numbers/mL of raw semen;

${ }^{c}$ Tissue culture infectious dose $\left(\mathrm{TCID}_{50}\right)$;

* Intraperitoneally.

\subsubsection{Swine bioassay study}

The pigs were randomly divided into 4 groups (Tab. I) and each group was housed in a separate room on arrival at the isolation facility. Each room was equipped with an ante-room where personnel protective equipment (face masks, boots, gloves, and disposable covers) were supplied for room entrance by animal care takers, and each room was ventilated separately. Animals were contained in a $1.5 \times 2.5 \mathrm{~m}$ pen supplied with a nipple drinker and a self feeder. Animals were fed ad libidum a balanced, pelleted, complete feed ration free of animal proteins and antibiotics (Nature's Made, Heartland Coop, IA, USA).

Inoculation was done intraperitoneally for all groups using an aseptic technique and a 24 gauge, $1 / 2$ inch hypodermic needle as described [54]. The bioassay-control group received $7 \mathrm{~mL}$ of PCV2 DNA-negative raw semen, the bioassay-PCV2a group received $7 \mathrm{~mL}$ PCV2a DNA-positive raw semen, and the bioassay-PCV2b group received $7 \mathrm{~mL}$ PCV2b DNA-positive raw semen. The number of PCV2 genomic copy numbers $/ \mathrm{mL}$ of raw semen was $10^{5.6}$ and $10^{5.8}$ for PCV2a and PCV2b, respectively. The PCV2a and PCV2b isolates shared $95.7 \%$ nucleotide sequence identity. The bioassay-positive group received $3 \mathrm{~mL}$ of PCV2a live virus (ISU-40895) generated by transfection of PK-15 cells with the PCV2a ISU-40895 infectious DNA clone [8] at a dose of $10^{4.5} \mathrm{TCID}_{50}$ combined with $4 \mathrm{~mL}$ of sterile saline.

Serum samples were collected prior to inoculation (Day 0 post inoculation; DPI 0) and weekly thereafter. On DPI 49, all pigs were humanely euthanized by lethal overdose of intravenous (auricular vein) pentobarbital (Fatal-Plus ${ }^{\circledR}$, Vortech Phamaceutical, LTD, Dearborn, MI, USA). At necropsy, gross lesions were assessed on each pig and tissues from all major organ systems were collected for microscopic examination and immunohistochemistry (IHC).

\subsubsection{Artificial insemination study}

The gilts were randomly divided into 3 treatment groups (Tab. II) and isolation rooms at 8 months of age. The general room set-up was similar to that described for the bioassay pigs. The gilts were housed in a $2 \times 4 \mathrm{~m}$ pen supplied with a nipple drinker. Animals were fed daily approximately $2.5 \mathrm{~kg}$ of a balanced ground corn-soy based complete feed ration free of animal proteins and antibiotics (Nature's Made). Prior to artificial insemination, gilts were

Table II. Artificial insemination study: Experimental design. Each sow was inseminated three times (dose $1,2,3) 24 \mathrm{~h}$ apart during estrus.

\begin{tabular}{lcccccc}
\hline \multirow{2}{*}{ Group } & \multirow{2}{*}{$n^{\mathrm{a}}$} & \multirow{2}{*}{ Inoculum } & \multirow{2}{*}{ Raw semen $^{\mathrm{b}}$} & \multicolumn{2}{c}{ Artificial insemination $^{\mathrm{b}}$} & \multirow{2}{*}{ Route } \\
\cline { 5 - 6 } & & & 1 st dose & 2nd and 3rd dose & \\
\hline Gilts-Control & 3 & PCV2-DNA-negative semen & - & - & - & AI* \\
Gilts-PCV2a & 3 & PCV2a-DNA-positive semen & $10^{5.6}$ & $10^{5.3}$ & $10^{4.4}$ & AI \\
Gilts-PCV2b & 3 & PCV2b-DNA-positive semen & $10^{5.8}$ & $10^{5.5}$ & $10^{4.6}$ & AI \\
\hline
\end{tabular}

a Number of pigs in each group;

${ }^{\mathrm{b}} \mathrm{PCV} 2$ genomic copy numbers $/ \mathrm{mL}$;

* Artificial insemination. 
individually synchronized for estrus detection for 17 consecutive days using a commercially available liquid altrenogest (Matrix ${ }^{\circledR}$, Intervet Inc., Millsboro, DE, USA), that was added to the daily feeding at the recommended dosage $(15 \mathrm{mg})$. Twenty-four hours after termination of the treatment, each animal received a $5 \mathrm{~mL}$ intramuscular injection of gonadotropin (P.G. $600^{\circledR}$, Intervet Inc.) and was then bred by artificial insemination upon estrus detection. Each gilt was artificially inseminated three times during standing estrus with $24 \mathrm{~h}$ between each insemination to ensure coverage of ovulation. Initially, $80 \mathrm{~mL}$ of $1: 1$ extended raw semen $(40 \mathrm{~mL}$ raw semen and $40 \mathrm{~mL}$ extender) (collected on the same day) was used. For second and third artificial insemination matings, semen extended to approximately 5 billion sperm per $80 \mathrm{~mL}$ dose was used $(5 \mathrm{~mL}$ of raw semen to $75 \mathrm{~mL}$ extender).

To evaluate a potential negative effect of the semen extender used on infectivity of the PCV2, an equal amount of extender was added to PCV2 live virus in a 1:1 dilution. In addition and as a control, PCV2 live virus was diluted with minimum essential medium (MEM) in a dilution of 1:1. The PCV2 titer was estimated by immunofluorescence assay (IFA) with PCV2 a specific antibody as described [8] at $0,8,24,48$, and $96 \mathrm{~h}$ post dilution.

Serum samples from all gilts were collected prior to insemination and weekly thereafter. At approximately 5 and 8 weeks post artificial insemination, ultrasonography was used to confirm pregnancy. Necropsy was performed at 105 days of gestation and gilts were euthanized by intravenous (auricular vein) overdose of pentobarbital. All fetuses from were immediately extracted and fetal serum was collected.

\subsection{Serology}

All weekly collected serum samples were analyzed for presence of anti-PCV2 IgG antibodies with an opening reading frame 2 (ORF2) based PCV2 ELISA as previously described [25]. A serum with a sample to positive ratio ( $\mathrm{s} / \mathrm{p})$ equal or greater than 0.2 was considered to be positive.

\subsection{Quantitative real-time polymerase chain reaction}

Serum samples collected weekly from the bioassay pigs and individual fetal serum samples

Page 4 of 11 (page number not for citation purpose) were tested for the presence and amount of PCV2 DNA by quantitative real-time PCR as described [27].

\subsection{Sequencing}

PCR products from the PCV2a or PCV2b positive semen, the PCV2 inoculum, and serum from one randomly selected pig at 49 DPI in each of the bioassay groups (bioassay-PCV2a, bioassayPCV2b, and bioassay-positive) was sequenced and compared to each other. A nested PCR was used to amplify the entire ORF2 gene for sequencing and subsequent sequence comparison as previously described [30].

\subsection{Necropsy}

At necropsy, percentage of lungs affected by lesions ranging from $0-100 \%$ [12] and presence and degree of lymphadenopathy were evaluated [27]. Both fresh tissues and tissues fixed in $10 \%$ buffered formalin were collected. Tissues included lung (all lobes), liver, spleen, kidney, tonsil, ileum, colon, thymus, multiple lymph nodes (tracheobronchial, mediastinal, mesenteric, iliac, superficial inguinal) and myocardium. In addition, uterus, ovary and placenta were collected from the breeding animals.

\subsection{Microscopic evaluation}

The formalin fixed tissue samples were routinely processed and stained with hematoxylin and eosin for microscopic evaluation. Lungs, lymph nodes, and other lymphoid tissues (tonsil and spleen) were scored for the presence and severity of PCV2associated lesions as previously described [28] by a veterinary pathologist blinded to the treatment group.

\subsection{Immunohistochemistry}

IHC staining for detection of PCV2-antigen in formalin fixed, paraffin embedded tissue was performed on selected lymphoid tissues (tracheobronchial, mediastinal, mesenteric, iliac, superficial inguinal, thymus, tonsil, spleen and Peyer's patches) collected from all bioassay pigs as described [51]. Additionally, sections of ovary, uterus, and lymphoid tissue (tonsil and iliac lymph node) from all gilts were tested by IHC for presence of PCV2 
Table III. Swine bioassay study: Incidence (number of pigs affected/number of pigs per group) of PCV2 DNA in serum (Serum PCR) and anti-PCV2 antibodies in serum (ELISA) by group at different days post inoculation (DPI).

\begin{tabular}{lccccccccc}
\hline \multirow{2}{*}{ Group } & \multirow{2}{*}{ Sample } & \multicolumn{10}{c}{ DPI } \\
\cline { 3 - 9 } & & 0 & 7 & 14 & 21 & 28 & 35 & 42 & 49 \\
\hline Bioassay-control & Serum PCR & $0 / 3$ & $0 / 3$ & $0 / 3$ & $0 / 3$ & $0 / 3$ & $0 / 3$ & $0 / 3$ & $0 / 3$ \\
& ELISA & $0 / 3$ & $0 / 3$ & $0 / 3$ & $0 / 3$ & $0 / 3$ & $0 / 3$ & $0 / 3$ & $0 / 3$ \\
Bioassay-PCV2a & Serum PCR & $0 / 3$ & $0 / 3$ & $0 / 3$ & $1 / 3$ & $2 / 3$ & $3 / 3$ & $3 / 3$ & $3 / 3$ \\
& ELISA & $0 / 3$ & $0 / 3$ & $0 / 3$ & $0 / 3$ & $1 / 3$ & $1 / 3$ & $2 / 3$ & $3 / 3$ \\
Bioassay-PCV2b & Serum PCR & $0 / 3$ & $0 / 3$ & $0 / 3$ & $2 / 3$ & $2 / 3$ & $3 / 3$ & $3 / 3$ & $3 / 3$ \\
& ELISA & $0 / 3$ & $0 / 3$ & $0 / 3$ & $0 / 3$ & $0 / 3$ & $0 / 3$ & $1 / 3$ & $2 / 3$ \\
Bioassay-positive & Serum PCR & $0 / 3$ & $3 / 3$ & $3 / 3$ & $3 / 3$ & $3 / 3$ & $3 / 3$ & $3 / 3$ & $3 / 3$ \\
& ELISA & $0 / 3$ & $0 / 3$ & $3 / 3$ & $3 / 3$ & $3 / 3$ & $3 / 3$ & $3 / 3$ & $3 / 3$ \\
\hline
\end{tabular}

* Pigs with a sample to positive ratio equal to or greater than 0.2 were considered positive.

antigen. The distribution and amount of PCV2 antigen in individually examined tissue sections were scored ranging from 0 (no signal) to 3 (strong signaling) as previously described [27].

\section{RESULTS}

\subsection{Swine bioassay study}

All DPI 0 serum samples were negative for anti-PCV2 antibodies. Furthermore, the bioassay-control pigs remained free of antiPCV2 IgG antibodies for the duration of the study. One of three bioassay-PCV2a pigs had detectable anti-PCV2 antibodies from DPI 28 onwards (Tab. III). The remaining two bioassay-PCV2a pigs developed anti-PCV2 IgG antibodies by DPI 49. Two of three bioassay-PCV2b pigs developed detectable anti-PCV2 antibodies by DPI 49. All three of the bioassay-positive pigs had detectable antiPCV2 IgG antibodies by DPI 14 and remained positive for the duration of the trial.

PCV2 DNA was not detected in the weekly collected bioassay-control serum samples for the entire duration of the study nor from any animal on DPI 0. PCV2 DNA was detected in $1 / 3$ bioassay-PCV2a pigs at DPI $21,2 / 3$ at DPI 28, and $3 / 3$ at DPI 35 (Tab. III). All pigs remained PCV2 viremic until termination of the study. Two of three bioassay-PCV2b pigs were positive for PCV2 DNA in serum on DPI 21 , and $3 / 3$ pigs were PCV2 DNA positive from DPI 35 until DPI 49. PCV2 DNA was detected in $3 / 3$ serum samples from bioassay-positive pigs on DPI 7, and all pigs in this group remained viremic until DPI 49. The sequence of the entire PCV2 ORF2 PCR product collected in each treatment group on DPI 49 was $99.9 \%$ similar to the original inoculum.

Macroscopic lesions were not present in the bioassay-control animals. Gross lesions in the bioassay-PCV2a animals included mild-tomoderate fibrinous peritonitis with mild lymphadenopathy (2/3), diffuse non-collapsing lungs (1/3), and liver abscessation (1/3). Bioassay-PCV2b gross lesions included fibrinous peritonitis (2/3) and mild lymphadenopathy (1/3). All bioassay-positive animals had diffuse non-collapsing lungs with mild-tomoderate lymphadenopathy in $2 / 3$ pigs.

Microscopically, 1/3 bioassay-control pigs had mild multifocal lymphocytic inflammation expanding interstitial lung parenchyma. The microscopic lesions in the bioassayPCV2a animals included moderate multifocal lymphohistiocytic interstitial pneumonia (3/3), mild multifocal lymphocytic interstitial nephritis (1/3), and mild multifocal lymphocytic myocarditis (1/3). Microscopic lesions in the bioassay-PCV2b pigs included mild-tomoderate multifocal lymphohistiocytic interstitial pneumonia in all pigs. Lesions in the bioassay-positive group included mild to moderate multifocal lymphohistiocytic interstitial 
Table IV. Effect of semen extender on the survivability of PCV2 in cell culture.

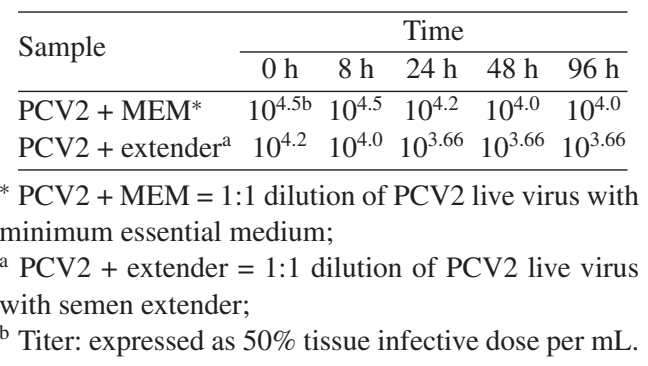

pneumonia (3/3), mild multifocal lymphocytic interstitial nephritis (3/3) and mild lymphoid depletion (1/3).

Low amounts of PCV2 antigen were detected in lymph node sections of $2 / 3$ bioassay-positive pigs. PCV2 antigen was not detected in tissue sections of bioassay-control pigs, bioassay-PCV2a pigs, or bioassayPCV2b pigs.

\subsection{Artificial insemination study}

In the extender-dilution-in-vivo-assay, the starting titer of the PCV2 live virus diluted with semen extender was determined to be $10^{4.2}$ TCID $_{50}$ per $\mathrm{mL}$ while the control virus stock diluted with MEM had a titer of $10^{4.5}$ TCID $_{50}$ per $\mathrm{mL}$ (Tab. IV). The PCV2 titers slightly decreased over time, and the final titer of PCV2 at $96 \mathrm{~h}$ post dilution was $10^{4.0} \mathrm{TCID}_{50}$ per $\mathrm{mL}$ and $10^{3.66} \mathrm{TCID}_{50}$ per $\mathrm{mL}$ for the MEM diluted PCV2 and the extender diluted PCV2, respectively (Tab. IV).

Three of 3 control gilts, 2/3 gilts-PCV2a, and $3 / 3$ gilts-PCV2b were confirmed pregnant by ultrasonography at 35 and 56 days post insemination. One animal in the gilt-PCV2a group was breed on two consecutive estrus cycles, but failed to become pregnant.

The total number of fetuses retrieved from the gilts-control group was 25 with litter sizes of 4, 7, and 14 fetuses (+1 mummy). The total number of fetuses retrieved from the gilts-PCV2a group was 16 with litters of 5 and 11 fetuses. The total number of fetuses retrieved from gilts-PCV2b group was 40 with litters of 9,13 , and 18 fetuses ( +1 mummy).
Gross lesions were not observed in any of the fetuses.

At the time of artificial insemination, all gilts were negative for anti-PCV2 antibodies as determined by ELISA ( $/ \mathrm{p}$ ratio < 0.2$)$. None of the gilts developed anti-PCV2 IgG antibodies during the 105 days post artificial insemination. No gross lesions were observed during necropsy, no microscopic lesions were present in examined tissues, and IHC staining of lymphoid tissue, ovary and uterus were negative for PCV2 antigen in all gilts. All 79 fetal serum samples collected at 105 days of gestation were negative for anti-PCV2 antibodies and for PCV2 DNA.

\section{DISCUSSION}

Transmission of PCV2 is presently not well characterized, however, detection of PCV2 DNA has been reported in secretions and excretions including feces, urine, saliva, ocular, nasal, colostrum and semen of infected pigs [1, 16, 18, 47-49]. Rapid spread of porcine circovirus associated disease (PCVAD) across North America in recent years has raised questions about the risk of transmission of PCV2 in semen; however, epidemiological investigation have not confirmed the relationship between PCV2 positive semen and incidence of PCVAD $[4,38,56]$.

Semen transmission of certain viruses has been documented and is considered economically important for the swine industry, especially with the wide usage of artificial insemination. A recent review summarized viruses potentially shed in boar semen [11]. Currently, many North American boar stud operations frequently test for the presence of PRRSV by many methods for surveillance purposes $[36,40]$, yet the presence of other viruses associated with reproductive failure including PCV2 are infrequently tested for, although in one report 30\% (13/43) of boars tested where found to contain PCV2 DNA in semen [23]. In other geographical locations, PCV2 DNA was detected in 28 of $60(47 \%)$ and 26 of $98(27 \%)$ semen samples obtained from 30 and 49 Korean swine herds [14, 15], 
$18 \%(86 / 472)$ of semen samples from Austrian and German boars [44], and 22\% (67/304) of semen samples collected from 4 Brazilian farms ${ }^{1}$. Other European countries have begun to test boar semen for exportation for the presence of PCV2 DNA to prevent the possible spread of PCVAD ${ }^{2}$.

The significance of PCV2 in semen is currently unknown and the purpose of this study was to try to expand the knowledge base on this topic. Due to the cytotoxicity of semen [45] and the non-cytopathic effect of PCV2 in cell culture, virus isolation techniques can be misleading and unrewarding. Thus, highly sensitive PCR methodologies are currently used to determine if PCV2 is present in semen. Polymerase chain reaction techniques can detect the presence of PCV2 DNA using small amounts of semen; however, positive PCR results do not necessarily correlate with presence of infectious virus. Previously, a swine bioassay model was developed to confirm the infectivity of PRRSV in semen [52]. In this study, a similar bioassay model was used to test the infectivity of PCV2 DNA present in semen.

The results of the PCV2 swine bioassay confirm that PCV2a and PCV2b present in semen are infectious as evidenced by the detection of PCV2 viremia, seroconversion in the recipients after inoculation, and microscopic lesions compatible with PCV2 infection in growing pigs. In the experimental PCV2 pig model using intranasal and/or intramuscular inoculations, anti-PCV2 antibodies can be detected between 21-28 DPI [27]. The delayed antibody response to PCV2 observed in pigs intraperitoneally injected with $\mathrm{PCV} 2$

\footnotetext{
${ }^{1}$ Ciacci-Zanella J.R., Zanella E.L., Locatelli M.L., Brambatti J.L., Simon N.L., Coldebella M., Detection of porcine circovirus 2 in semen collected from naturally infected boar studs in Brazil, Proc. 5th International Symposium on Emerging and Reemerging Pig Disease, Karkow, 2007, p. 94.

${ }^{2}$ Wallgren P., Blomqvist G., Thorén P., Elander J., Wallgren M., Incidence of PCV2 in semen collected at Swedish boar stations, Proc. 20th International Pig Veterinary Society Congress, Durban, 2008, volume II, p. 62.
}

DNA-positive semen when compared to pigs inoculated with PCV2 live virus may be dose related. Additional considerations for delayed response in antibody production may be due to natural constituents present in semen [55] or different antigens present competing for an immunological response [6]. The peritonitis present at necropsy may have been in part induced by antigens present in the semen or possibly by bacterial contamination during intraperitoneal inoculation and this may have contributed to some of the microscopic lesions observed. Additionally, PCV2 antigen was not detected in tissues from bioassay-PCV2a pigs, or bioassay-PCV2b pigs in this study. This result may due to the detection limits of IHC because it has been previously estimated that $10^{8}$ PCV2 genomic copies are needed in tissue sections for visualization of IHC signaling [2].

Artificial insemination with semen containing PCV2 DNA did not result in dam or fetal infection in this study even with the initial insemination being diluted 1:1 with extender. This may indicate that low exposure to PCV2 in semen may be of lesser consequence. In most field situations, a single semen collection from a boar is typically diluted into many insemination doses and commonly mixed with semen samples from other boars further decreasing the amount of PCV2 in a dose of semen typically used for artificial insemination. However, PCV2 has the ability to infect and replicate in different stages (zona pellucida free morulae, early blastocysts and hatched blastocysts) of in vivo produced embryonic cells with increasing susceptibility of infection in the later stages [22]. It has been shown that PCV2 with an approximate diameter of $17 \mathrm{~nm}$ in size did not infect intact zona pellucida morulae, although $20 \mathrm{~nm}$ diameter fluorescent beads could pass through zona pellucida pores. PCV2 is a difficult virus to inactivate, thus PCV2 present in semen may be a risk for infection [22]. PCV2 is associated with the cell fraction portion of semen [33]. This may indicate that there is a higher risk of PCV2 infection during fertilization because spermatozoa may be associated with PCV2 DNA.

(page number not for citation purpose) Page 7 of 11 
Differences in virulence and tropism of PCV2 isolates have been suggested as a possible reason for PCV2-associated reproductive failure when compared to PCV2-associated diseases in growing swine [7, 24]. Two PCV2 isolates were used in this study and both originated from growing pigs with PCVAD. However, it is unknown whether these isolates were also associated with reproductive failure in the field.

In swine, the route of PCV2 exposure is likely fecal-oral [46] and fetal infection has been associated with viremia of the dam [34]. It was recently reported that reproductive failure was associated with insemination of PCV2 spiked semen in PCV2 positive dams [39]. The dams were intranasally inoculated 60 days prior to insemination, and it was unknown whether dams were still viremic at the time of insemination with PCV2 spiked semen. The dams may have been viremic which could have contributed to the reproductive failure [39]. In support of this, in a different study it has been shown that PCV2 experimentally inoculated gilts had detectable PCV2 DNA in peripheral blood mononuclear cells at 63 DPI [35].

The results of our study indicate that PCV2 DNA present in semen ranging from $10^{5.6}$ to $10^{5.8}$ genomic copies $/ \mathrm{mL}$ did not cause reproductive failure, development of dam associated anti-PCV2 antibodies, or fetal infection. In addition, the semen extender used in the study was found to have only a minimal effect on the viability and infectivity of PCV2.

The amount of PCV2 present in semen is likely determining whether PCV2 infection occurs. Previously, non-extended raw semen has been shown to infect PRRS negative gilts [58], but extended semen, though causing a reduction of pregnancy rates, did not cause seroconversion or infection [53]. This indicates that the dose of viruses in semen plays a major role in transmissibility. In further support of this, only $20 \%$ of negative gilts inseminated with PRRSV at doses of 2000 and $20000 \mathrm{TCID}_{50} / 50 \mathrm{~mL}$ semen seroconverted while semen containing PRRSV at $\geqslant 200000 \mathrm{TCID}_{50} / 50 \mathrm{~mL}$ semen was infectious in $100 \%$ of the negative gilts ${ }^{3}$. Alternatively, other possible explanations for not having PCV2 infection in the gilts may be related to the increased numbers of inflammatory cells that are present in the uterus associated with innate immunity during proestrus, estrus, and early diestrus [5], age related differences in susceptibility, or the influence of altrenogest (Matrix ${ }^{\circledR}$ ) on and uterine defense mechanisms [10].

In summary, we determined that PCV2a and PCV2b shed in semen were infectious in a swine bioassay model. We also determined that low doses of PCV2 $\left(10^{5.6}-10^{5.8}\right.$ PCV2 genomic copies per $\mathrm{mL}$ ) in extended semen when used for artificial insemination does not cause reproductive failure, seroconversion, or PCV2 viremia in naïve gilts and their offspring. The authors acknowledge that the amount of PCV2 present in semen is a possible contributing factor in transmissions of PCV2 via semen to swine herds that utilize artificial insemination. We also are aware of potential PCV2 isolate differences in association with reproductive failure. Further investigations are needed and currently under way.

Acknowledgements. We thank the National Pork Board and the Iowa Livestock Health Advisory Council for providing funding of the studies, Newsham Choice Genetics for providing the animals used in the studies and IMV International for supplies. The authors would also like to thank Dr Phil Gauger, Matt Boogerd, Dr Abby Patterson, and Paul Thomas for their assistance with animal care and collection of samples throughout the study.

\section{REFERENCES}

[1] Bolin S.R., Stoffregen W.C., Nayar G.P., Hamel A.L., Postweaning multisystemic wasting syndrome induced after experimental inoculation of cesareanderived, colostrum-deprived piglets with type 2 porcine circovirus, J. Vet. Diagn. Invest. (2001) 13:185-194.

\footnotetext{
${ }^{3}$ Benfield D., Nelson C., Steffen M., Rowland R., Transmission of PRRSV by artificial insemination using extended semen seeded with different concentrations of PRRSV, Proc. 31st American Association of Swine Practitioners, Indianapolis, 2000, pp. 405-408.
} 
[2] Brunborg I.M., Moldal T., Jonassen C.M., Quantitation of porcine circovirus type 2 isolated from serum/plasma and tissue samples of healthy pigs and pigs with postweaning multisystemic wasting syndrome using a TaqMan-based real-time PCR, J. Virol. Methods (2004) 122:171-178.

[3] Christopher-Hennings J., Nelson E.A., Nelson J.K., Hines R.J., Swenson S.L., Hill H.T., et al., Detection of porcine reproductive and respiratory syndrome virus in boar semen by PCR, J. Clin. Microbiol. (1995) 33:1730-1734.

[4] Cottrell T.S., Friendship R.M., Dewey C.E., Allan G., Walker I., McNeilly F., A study investigating epidemiological risk factors for porcine circovirus type II in Ontario, Pig J. (1999) 44:10-17.

[5] Dalin A.M., Kaeoket K., Persson E., Immune cell infiltration of normal and impaired sow endometrium, Anim. Reprod. Sci. (2004) 82-83:401-413.

[6] Dostal J., Veselsky L., Proteins in the seminal plasma and the accessory sexual gland fluids of the boar, J. Reprod. Fertil. (1972) 30:255-267.

[7] Farnham M.W., Choi Y.K., Goyal S.M., Joo H.S., Isolation and characterization of porcine circovirus type-2 from sera of stillborn fetuses, Can. J. Vet. Res. (2003) 67:108-113.

[8] Fenaux M., Halbur P.G., Haqshenas G., Royer R., Thomas P., Nawagitgul P., et al., Cloned genomic DNA of type 2 porcine circovirus is infectious when injected directly into the liver and lymph nodes of pigs: characterization of clinical disease, virus distribution, and pathologic lesions, J. Virol. (2002) 76:541-551.

[9] Gerrits R.J., Lunney J.K., Johnson L.A., Pursel V.G., Kraeling R.R., Rohrer G.A., Dobrinsky J.R., Perspectives for artificial insemination and genomics to improve global swine populations, Theriogenology (2005) 63:283-299.

[10] Gradil C., Dubuc C., Eaglesome M.D., Porcine reproductive and respiratory syndrome virus: seminal transmission, Vet. Rec. (1996) 138:521-522.

[11] Guerin B., Pozzi N., Viruses in boar semen: detection and clinical as well as epidemiological consequences regarding disease transmission by artificial insemination, Theriogenology (2005) 63:556-572.

[12] Halbur P.G., Paul P.S., Frey M.L., Landgraf J., Eernisse K., Meng X.J., et al., Comparison of the pathogenicity of two US porcine reproductive and respiratory syndrome virus isolates with that of the Lelystad virus, Vet. Pathol. (1995) 32:648-660.

[13] Johnson C.S., Joo H.S., Direksin K., Yoon K.J., Choi Y.K., Experimental in utero inoculation of lateterm swine fetuses with porcine circovirus type 2, J. Vet. Diagn. Invest. (2002) 14:507-512.
[14] Kim J., Han D.U., Choi C., Chae C., Differentiation of porcine circovirus (PCV)-1 and PCV-2 in boar semen using a multiplex nested polymerase chain reaction, J. Virol. Methods (2001) 98:25-31.

[15] Kim J., Han D.U., Choi C., Chae C., Simultaneous detection and differentiation between porcine circovirus and porcine parvovirus in boar semen by multiplex seminested polymerase chain reaction, J. Vet. Med. Sci. (2003) 65:741-744.

[16] Krakowka S., Ellis J.A., Meehan B., Kennedy S., McNeilly F., Allan G., Viral wasting syndrome of swine: experimental reproduction of postweaning multisystemic wasting syndrome in gnotobiotic swine by coinfection with porcine circovirus 2 and porcine parvovirus, Vet. Pathol. (2000) 37:254-263.

[17] Ladekjær-Mikkelsen A.S., Nielsen J., Storgaard T., Bøtner A., Allan G., McNeilly F., Transplacental infection with $\mathrm{PCV}-2$ associated with reproductive failure in a gilt, Vet. Rec. (2001) 148:759-760.

[18] Larochelle R., Bielanski A., Muller P., Magar R., PCR detection and evidence of shedding of porcine circovirus type 2 in boar semen, J. Clin. Microbiol. (2000) 38:4629-4632.

[19] Madsen K.S., Management of disease control and epidemics in AI in Denmark, Theriogenology (2005) 63:585-594.

[20] Madson D.M., Ramamoorthy S., Kuster C., Pal N., Meng X.J., Halbur P.G., Opriessnig T., Characterization of shedding patterns of porcine circovirus type 2a and PCV2b in experimentally inoculated mature boars, J. Vet. Diagn. Invest. (2008) 20:725-734.

[21] Maes D., Nauwynck H., Rijsselaere T., Mateusen B., Vyt P., De Kruif A., Van Soom A., Diseases in swine transmitted by artificial insemination: An overview, Theriogenology (2008) 70:1337-1345.

[22] Mateusen B., Sanchez R.E., Van Soom A., Meerts P., Maes D.G., Nauwynck H.J., Susceptibility of pig embryos to porcine circovirus type 2 infection, Theriogenology (2004) 61:91-101.

[23] McIntosh K.A., Harding J.C., Parker S., Ellis J.A., Appleyard G.D., Nested polymerase chain reaction detection and duration of porcine circovirus type 2 in semen with sperm morphological analysis from naturally infected boars, J. Vet. Diagn. Invest. (2006) 18:380-384.

[24] Meehan B.M., McNeilly F., McNair I., Walker I., Ellis J.A., Krakowka S., Allan G.M., Isolation and characterization of porcine circovirus 2 from cases of sow abortion and porcine dermatitis and nephropathy syndrome, Arch. Virol. (2001) 146:835-842.

[25] Nawagitgul P., Harms P.A., Morozov I., Thacker B.J., Sorden S.D., Lekcharoensuk C., Paul P.S.,

(page number not for citation purpose) Page 9 of 11 
Modified indirect porcine circovirus (PCV) type 2based and recombinant capsid protein (ORF2)-based enzyme-linked immunosorbent assays for detection of antibodies to PCV, Clin. Diagn. Lab. Immunol. (2002) 9:33-40.

[26] O'Connor B., Gauvreau H., West K., Bogdan J., Ayroud M., Clark E.G., et al., Multiple porcine circovirus 2-associated abortions and reproductive failure in a multisite swine production unit, Can. Vet. J. (2001) 42:551-553.

[27] Opriessnig T., Yu S., Gallup J.M., Evans R.B., Fenaux M., Pallares F., et al., Effect of vaccination with selective bacterins on conventional pigs infected with type 2 porcine circovirus, Vet. Pathol. (2003) 40: $521-529$

[28] Opriessnig T., Thacker E.L., Yu S., Fenaux M., Meng X.J., Halbur P.G., Experimental reproduction of postweaning multisystemic wasting syndrome in pigs by dual infection with Mycoplasma hyopneumoniae and porcine circovirus type 2, Vet. Pathol. (2004) 41:624-640.

[29] Opriessnig T., Kuster C., Halbur P.G., Demonstration of porcine circovirus type 2 in the testes and accessory sex glands of a boar, J. Swine Health Prod. (2006) $14: 42-45$.

[30] Opriessnig T., McKeown N.E., Zhou E.M., Meng X.J., Halbur P.G., Genetic and experimental comparison of porcine circovirus type 2 (PCV2) isolates from cases with and without PCV2-associated lesions provides evidence for differences in virulence, J. Gen. Virol. (2006) 87:2923-2932.

[31] Opriessnig T., Meng X.J., Halbur P.G., Porcine circovirus type 2 associated disease: Update on current terminology, clinical manifestations, pathogenesis, diagnosis, and intervention strategies, J. Vet. Diagn. Invest. (2007) 19:591-615.

[32] Opriessnig T., Ramamoorthy S., Madson D.M., Patterson A.R., Pal N., Carman S., et al., Differences in virulence among porcine circovirus type 2 isolates are unrelated to cluster type $2 \mathrm{a}$ or $2 \mathrm{~b}$ and prior infection provides heterologous protection, J. Gen. Virol. (2008) 89:2482-2491.

[33] Pal N., Huang Y.W., Madson D.M., Kuster C., Meng X.J., Halbur P.G., Opriessnig T., Development and validation of a duplex real-time PCR assay for the simultaneous detection and quantification of porcine circovirus type 2 and an internal control on porcine semen samples, J. Virol. Methods (2008) 149: 217-225.

[34] Park J.-S., Kim J., Ha Y., Jung K., Choi C., Lim J.-K., et al., Birth abnormalities in pregnant sows infected intranasally with porcine circovirus 2, J. Comp. Pathol. (2005) 132:139-144.

Page 10 of 11 (page number not for citation purpose)
[35] Pensaert M.B., Sanchez R.E. Jr., LadekjærMikkelsen A.S., Allan G.M., Nauwynck H.J., Viremia and effect of fetal infection with porcine viruses with special reference to porcine circovirus 2 infection, Vet. Microbiol. (2004) 98:175-183.

[36] Reicks D.L., Munoz-Zanzi C., Rossow K., Sampling of adult boars during early infection with porcine reproductive and respiratory syndrome virus for testing by polymerase chain reaction using new blood collection technique (blood swab method), J. Swine Health Prod. (2006) 14:258-264.

[37] Robinson J.A., Buhr M.M., Impact of genetic selection on management of boar replacement, Theriogenology (2005) 63:668-678.

[38] Rose N., Larour G., Le Diguerher G., Eveno E., Jolly J.P., Blanchard P., et al., Risk factors for porcine post-weaning multisystemic wasting syndrome (PMWS) in 149 French farrow-to-finish herds, Prev. Vet. Med. (2003) 61:209-225.

[39] Rose N., Blanchard P., Cariolet R., Grasland B., Amenna N., Oger A., et al., Vaccination of porcine c ircovirus type 2 (PCV2)-infected sows against porcine parvovirus (PPV) and erysipelas: Effect on postweaning multisystemic wasting syndrome (PMWS) and on PCV2 genome load in the offspring, J. Comp. Pathol. (2007) 136:133-144.

[40] Rovira A., Clement T., Christopher-Hennings J., Thompson B., Engle M., Reicks D., MunozZanzi C., Evaluation of the sensitivity of reversetranscription polymerase chain reaction to detect porcine reproductive and respiratory syndrome virus on individual and pooled samples from boars, J. Vet. Diagn. Invest. (2007) 19:502-509.

[41] Rovira A., Reicks D., Munoz-Zanzi C., Evaluation of surveillance protocols for detecting porcine reproductive and respiratory syndrome virus infection in boar studs by simulation modeling, J. Vet. Diagn. Invest. (2007) 19:492-501.

[42] Sanchez R.E. Jr., Nauwynck H.J., McNeilly F., Allan G.M., Pensaert M.B., Porcine circovirus 2 infection in swine foetuses inoculated at different stages of gestation, Vet. Microbiol. (2001) 83: 169-176.

[43] Sanchez R.E. Jr., Meerts P., Nauwynck H.J., Pensaert M.B., Change of porcine circovirus 2 target cells in pigs during development from fetal to early postnatal life, Vet. Microbiol. (2003) 95:15-25.

[44] Schmoll F., Prevalence of PCV2 in Austrian and German boars and semen used for artificial insemination, Theriogenology (2008) 69:814-821.

[45] Schultz R.D., Adams L.S., Letchworth G., Sheffy B.E., Manning T., Bean B., A method to test large numbers of bovine semen samples for viral 
contamination and results of a study using this method, Theriogenology (1982) 17:115-123.

[46] Segalés J., Allan G.M., Domingo M., Porcine circovirus diseases, Anim. Health Res. Rev. (2005) 6:119-142.

[47] Shibata I., Okuda Y., Yazawa S., Ono M., Sasaki T., Itagaki M., et al., PCR detection of porcine circovirus type 2 DNA in whole blood, serum, oropharyngeal swab, nasal swab, and feces from experimentally infected pigs and field cases, J. Vet. Med. Sci. (2003) 65:405-408.

[48] Shibata I., Okuda Y., Kitajima K., Asai T., Shedding of porcine circovirus into colostrum of sows, J. Vet. Med. B Infect. Dis. Vet. Public Health (2006) 53:278-280.

[49] Sibila M., Calsamiglia M., Segalés J., Blanchard P., Badiella L., Le Dimna M., et al., Use of a polymerase chain reaction assay and an ELISA to monitor porcine circovirus type 2 infection in pigs from farms with and without postweaning multisystemic wasting syndrome, Am. J. Vet. Res. (2004) 65:88-92.

[50] Singleton W.L., State of the art in artificial insemination of pigs in the United States, Theriogenology (2001) 56:1305-1310.

[51] Sorden S.D., Harms P.A., Nawagitgul P., Cavanaugh D., Paul P.S., Development of a polyclonalantibody-based immunohistochemical method for the detection of type 2 porcine circovirus in formalinfixed, paraffin-embedded tissue, J. Vet. Diagn. Invest. (1999) 11:528-530.

[52] Swenson S.L., Hill H.T., Zimmerman J.J., Evans L.E., Landgraf J.G., Wills R.W., et al., Excretion of porcine reproductive and respiratory syndrome virus in semen after experimentally induced infection in boars, J. Am. Vet. Med. Assoc. (1994) 204:1943-1948.
[53] Swenson S.L., Hill H.T., Zimmerman J.J., Evans L.E., Wills R.W., Yoon K.J., et al., Artifical insemination of gilts with porcine reproductive and respiratory syndrome (PRRS) virus-contaminated semen, Swine Health Prod. (1994) 2:19-23.

[54] Thomas P.J., Opriessnig T., Juhan N.M., Meng X.J., Halbur P.G., Planned exposure to porcine circovirus type 2 by serum injection is not effective at preventing porcine circovirus associated disease, J. Swine Health Prod. (2007) 15:330 338.

[55] Veselsky L., Dostal J., Zelezna B., Effect of boar seminal immunosuppressive component on humoral immune response in mice, Am. J. Reprod. Immunol. (1997) 38:106-113.

[56] Wallgren P., Hasslung F., Bergstrom G., Linder A., Belak K., Hard af Segerstad C., et al., Postweaning multisystemic wasting syndrome - PMWS. The first year with the disease in Sweden, Vet. Q. (2004) 26:170-187.

[57] West K.H., Bystrom J.M., Wojnarowicz C., Shantz N., Jacobson M., Allan G.M., et al., Myocarditis and abortion associated with intrauterine infection of sows with porcine circovirus 2, J. Vet. Diagn. Invest. (1999) 11:530-532.

[58] Yaeger M.J., Prieve T., Collins J., ChristopherHennings J., Nelson E., Benfield D., Evidence for the transmission of porcine reproductive and respiratory syndrome (PRRS) virus in boar semen, Swine Health Prod. (1993) 1:7-9.

[59] Yoon K.J., Jepsen R.J., Pogranichniy R.M., Sorden S., Stammer R., Evans L.E., A novel approach to intrauterine viral inoculation of swine using PCV type 2 as a model, Theriogenology (2004) 61: $1025-1037$. 